\title{
Business conjuncturality on the topic of personal mobility using electric automobiles
}

\author{
Ileana GAVRILESCU \\ The Bucharest University of Economic Studies, Bucharest, Romania \\ gavrilescu_ileana@yahoo.com
}

\begin{abstract}
The present article seek to continue last year's research by improving upon the subjects of current business models pertaining to personal mobility by way of electric automobiles, the efficiency of said models and by eventually developing a propitious business model, tailored to specificities of this domain. While the proposed topic is circumscribed within the general preoccupation with the rehabilitation of the natural environment through a better use of renewable energy, our fascination stems from the fact that personal mobility with the use of electric vehicles is one of the most dynamic and interesting social, economic and cultural worldwide phenomenon of the last decade. This topic has been broached, under different titles, by a number of researchers. After a significant amount of research on the subject, we realised that the importance of some of the thematic problem's determining factors has not been sufficiently emphasised neither in the theoretical findings of the most current research nor has it been sufficiently considered and practiced by the industry's "principal players" - the entrepreneurs and the managers. The satisfaction associated with this newly formed revelation as well as the confidence to further pursue this line of inquiry have been significantly marked by the realisation that the same concerns have already been touched upon by authors such as Christian Lerch, Fabian Kley, David Dallinger, Thomas Budde Christensen, Peter Wells, Liana Cipcigan. Any analysis of the subject matter is further complicated by the current economic turbulence. Therefore, this article aims to provide not only a nuanced understanding and a clear, exact and correct interpretation of some of the most important "factors/variables" involved but also reconsider the significance of said "factors/variables" within the context of the proposed research theme, so that based on the results of our research we might define a epistemologically useful yet practical concept. In any case, the present articles seeks to provoke further analysis and debate over the conjectural nature of innovative business models applicable to the electrical car mobility field.
\end{abstract}

Keywords: electric mobility, business model, social-economic conjuncture, economic inventiveness, turbulent economic environment, entrepreneurship, sustainability.

\begin{abstract}
Abbreviations EV = electric vehicle; PHEV = a plug-in hybrid electric vehicle; PEV = any vehicle that can be plugged in (either a plug-in hybrid or an all-electric vehicle); PMEC = personal mobility with electric car; $\mathrm{BMEC}=$ business model for electric cars
\end{abstract}

\section{Introduction}

From the generic definition of the business model, as a logical concept of strategic orientation through which an organization aims to maximize its internal and external potential both to meet the needs of society and to remain competitive in the long term, we seek to determine the degree and form that a Business Model for Electric Vehicles (BMEC) can take shape, in a turbulent economic environment, while at the same time offer a viable, valid, sustainable and even scalable alternative approach to existing business models. The instability that characterises the global economy, especially after the 2008 recession, is of course a result of the synergy of the economic mechanism.

Therefore, at the subsystem level, instability and unpredictability are also found in the constituent factors of a business, and the Electric Vehicle Mobility (PMEC) is not only an exception, but also one of the most "tectonic". That is why it comes as no surprise that - for example, one of the big problems faced by any Electric Vehicle (EV) or 
Plug-in Electric Vehicle (PHEV) manufacturer is, "How can we reconcile the design of a car - especially an electric car, which must last for more than ten years in order to ensure the loyalty of its customers, with the rapid pace of technological progress of late, which can, in two or three years' time render any new project obsolete?" In turn, business theory scholars with EVs and PHEVs are trying to encompass in a logical, clear, relevant and convincing vision a business model that would help companies attach more added value to their proposition as well as propose a new value for the client, to ensure not only their survival but also their success, even in the face of stiff competition.

It seems that all of the authors and all of their models, Alexander Osterwalder and his model - Business Model Canvas (Osterwalder, Pigneur and Tucci, 2005), are the most credited and therefore the most popular. Through the analysis of variant factors characterised by a high level of unpredictability, such as - among other things the (uncertain) ability of the electrical systems to ensure the need for an increasing number of electric cars, the recurrent and often arbitrary political interference into the PMEC phenomenon - by way of regulation and advantages, the under developed compatibility created by some producers (who are responsible for some technical and technological mistakes, execution errors, incidents and accidents, administrative mistakes, etc.), a lack of professionalism on the dealer's part - on the retail side of the business as well as in the way the actual promotion is done (lack of willingness to abandon the "showroom" and adopt more modern way of promoting the product), we discovered that all these variant factors, as well as others specific to the electric automobile business, cannot be subsumed - as is - into the "nine blocks" model that defines the Canvas business model. This is due to the fact that the Canvas Model - like most other business models - does not really work as a useful and comprehensive practical guide but rather as an extremely useful organising tool, whose great utility lies in a pleasant interface that offers the possibility of global, and thus unitary, visual supervision of all business-specific "labels". The Canvas model thus prevents the decision maker prevents from overlooking a possible course of action, especially if the canvas - fixed on the wall in front of the desk, can be seen at all times.

The topic of "The conjectural nature of businesses involving personal mobility through the use of an automobile" can (also) refer to the origin of these businesses, which did not come into being suddenly or naturally. The relatively recent businesses dealing with PMEC come as a direct response to the demand made by environmental organisations and administrations regarding the reduction of noxious fumes released into the atmosphere - the release of which being the leading cause behind the global climate change. However, the political stakes of these administrations also revolve around reducing the dependence on petroleum products, which are to a great extent imported.

But the theme proposed here can also refer to the complex continuous determination which, as a rule, society - and especially its economic and financial environment - has in general over all affairs, and in the context of this determination it can refer equally as well to the opportunism of businesses, which, beyond "natural" appearance and official statements, often do not hesitate to arrogate, even cynically, any favourable circumstances. The new business models in general, including those customised for electric mobility, are a great case, for example, of the value proposition that the market supplier (mainly the manufacturer and the trader) would offer unconditionally to his "new" customer, as if it would be a "merciful" concession sustained by his own well-being, though, as we know, that is not the case. "That is, the cost of pollution is not paid directly by the customer, but it spreads over to the rest of 
society.", says David Sallay, in a very interesting article (Sallay, 2013), suggesting one possible indicator that lies closer to the truth. In another article, entitled "Electric Cars and Electric Mobility - Statistics \& Facts," we also find concrete data: "As of 2016, Norway is awarding some 20,000 U.S. dollars per electric vehicle. "(statista.com, 2018) and in the article" Not fully charged: Tax incentives for employer-provided electric cars", Dimitropoulos and his co-signatories very clearly define the situation we find ourselves in: "We find that the welfare losses caused by these policies are substantial and even outweigh the foregone tax revenue."

Thus, in economy as in politics, the law of universal preservation - extrapolated from the laws of conservation of matter and energy, while preserving its essence - and by preserving the "actors on stage", could be paraphrased, in a lavoisier manner: "Nothing is lost, everything is ... transferred! "

\section{Literature review, between detraction and enthusiasm}

The field of personal mobility with the use of electrical automobiles (PMEC) has been, for the past decade, in an effervescently inventive state, technology-wise and in a feverish search for business models capable of ensuring the maximum possible yield and true sustainability. Major changes have a habit of occurring overnight. The ink wasn't even dry on the accolades for the Tesla concept as well as for the innovative business vision of Elon Musk - the visionary behind car, when bad things started to happen and the ground shifted from under the initial myth. Engineering flaws and execution errors, incidents and accidents, delayed delivery times and other unkept promises, summary dismissals, money returned to buyers enrolled in waiting lists - all of these represent both a failure to integrate the values it set out with as well as missed opportunities for client satisfaction. On the other hand, the great German builders, who "slept" until 2013 - compared to the USA, Japan, China and the rest of Europe, seem want to return to the pole position, have been seen reuniting forces and coming on the market today with models of extraordinary performance and as well as developing a unitary European infrastructure for battery charging stations.

Today, when the performance of electric automobiles has equalled that of traditional cars and is poised to someday soon overtake(estimates point to the year 2020), many people interested in personal mobility agree that the classic business model - (production, quality, performance, endowment, and reliability), and distribution / distribution - most often promoted by advertising - done only through sales agents and targeted on a case by case offer (a customer $=$ a car) can no longer match the moment in time, much less the business of electric cars (EV).

The optimistic psychology favourable to today's "Business Model for Electric Cars" (BMEC) is obviously due to the cutting-edge approach of courageous entrepreneurs (among whom Elon Musk is the most "re-known"), the courage of government policies (clearly favourable to environmental mobility ), but also to the enthusiasm of many customer-users. All of these major factors, who have deliberately assumed the risks of a radical transition, have already changed the face of automobile personal mobility in many areas of the world. The new BMECs offer benefits by reconsidering almost the whole concept of the business - namely by continuously raising the technical performance of cars and recharging infrastructure through a new type of flexibility and loyalty to suppliers, by reorienting all efforts towards satisfaction and loyalty to the client and respecting the political and administrative rules of protection aimed towards the preservation of the environment. 
However, beyond the inherent difficulty of promoting BMECs in this manner, we see how the confusing variance of some of their key factors overlaps, plus the fluctuation of other factors that - we think now - were much too easy to "overlook", or worse, "not even take into consideration".

If the overall picture of the general strategic categories of a business - whether of a technical or technological, mercantile, social, financial, legislative, normative, political and cultural nature - remains and will remain as immutable (by its generic, essential and fundamental character), the factors that are included or circumscribed in these categories have recently undergone such a spectacular variation and mutation that some of these factors have even disappeared altogether, and those remaining in the game as well as those that have appeared in context overnight, seem at first glance to no longer be rigorously quantifiable and controlled by traditional mathematics. Obviously, the particular change in some of the factors puts into question the relevance and compatibility of the categories they are part of, as well as of their entire system.

Energy-related issues in general, the continuous degradation of the natural environment and urban-environmental disaster (calamities, catastrophes), the advantages granted to the customer by the producer and dealer, the advantages granted to the buyer by governments, the incentives granted by governments to producers and dealers, the difficulty in increasing efficiency (increased capacity, ultrafast load, lower weight, lower price, etc.), the reconsideration of the mobility needs of the contemporary world or the market itself - determined by the most unique criteria, these are just a few examples of variables that can influence in a conjectural key essentially, even in the short term, both the development of electric mobility and the re-conceptualization of appropriate business models.

All of these motives and many more - of a more or less random nature, tend to give any theoretical debates over the efficiency of business models pertaining to the electricity-based mobility field (BMEC) a certain pioneering or even missionary feel. Moreover, actual start-ups as well as practical developments over the course of several businesses belonging to this field have been so far attempted in a more or less arbitrary fashion, marred by stallings and improvisations, with some even petering out - as was previously mentioned in a previous article (Gavrilescu, 2017).

The "feverishness" with which the development of new business models or the adaptation of existing ones to better suit the sustainability and scalability needs are approached, is not a characteristic to be found solely in the electrical mobility field, but rather encompasses every economic sphere. Here is how, for example, two remarkable analysts - Adrian Tanţău and Mohammadreza Khorshidi, highlight the necessity of a more adequate conjuncturalization of some business models particular to the oil industry: "For the oil industry, new business models need to be developed to describe the specificities of this industry and take into account the new objectives after the global oil crisis." (Tanțău and Khorshidi, 2016).

Some authors nurse a fundamental doubt regarding the general approach towards electricity-based mobility and seek to deconstruct, piece by piece, the authenticity and naturalness of the arguments in favour. For example, in an article entitled Cum să-ți furi căciula",Oproescu - a respected author, judging by the size of his audience, seeks to promote the idea that "if we would ask ourselves where the electrical current stored in our automobiles comes from and if we would do a little bit of research...,we would transform the electricity-based automobile into a true catastrophe. "The author's argument is that the share in the energy production of the non-polluting hydro-electric power plant is too small compared to the entire energy supply, as is the 
case with solar and wind power plants, and the "over-night" construction of a truly efficient nuclear power plant does not yet represent a priority actually to be found in policy (Oproescu, 2017).

On the same note, we have the opinion of Crânganu, professor of Geology at New York State University, author of numerous studies published in leading journals and "PSC Research Incentive Award" laureate: "If the electricity necessary to power the batteries comes from coal-based thermo-electric power plant, then the situation is not so pink anymore: the total emissions of suspended powders with a diameter greater than 2.5 microns (PM 2.5) and of sulphur oxides can increase significantly..., Detractors of the electricity-based automobile draw attention to the fact that, through externalisation, the AEs generate a series of harmful events that directly affect the environment: a) greenhouse gas emissions through the use of electricity generated from non-renewable sources; b) pollution resulting from the production and improper disposal of batteries and c) high levels of water consumption."(Crânganu, 2016).

Quite recently, towards the end of 2017, in an interview for the Automotive News portal, the former Ford, Chrysler, BMW, Opel senior executive and current General Motors vice-president looked similarly distrustful of the future: "It saddens me to say it, but we are approaching the end of the automotive era". He then went on to say that "Everyone will have 5 years to get their car off the road or sell it for scrap", (Lutz, 2017).

With a mix of pessimism and optimism regarding the future of mankind in general and of electric mobility in particular, Dieter Zetsche - director at Mercedes-Benz, nominated by Time Magazine in 2006 as being part of the top 100 most influential personalities and designated "Entrepreneur of the Year" in 2008 by the German mass media, anticipates, in a video that has since become viral on the internet, that traditional automobile maker will decline and die in the near future, while Tesla, Google and Apple will revolutionise the transportation industry and that through the proliferation of electric and/or autonomous automobiles the stress felt by people will significantly decrease, the air will once again become breathable, the cities will become much cleaner, calmer and quieter and last but not least, the death rate caused by traffic accidents will decrease from $1 / 100.000 \mathrm{~km}$. to $1 / 10.000 .000 \mathrm{~km}$. The two most interesting business predictions, from our "conjectural" point of view are that: "If it doesn't work with your phone, forget the idea. And any idea designed for success in the 20 th century is doomed to failure in the 21st century." And when the same Dieter Zetsche said that "The engineers at Volkswagen and Audi are terrified of their counterparts from Tesla", it is clear that he was referring not only to the high technical nature of Tesla automobiles but also to the business model that Tesla applied when it remarkably overtook the competition as well as to the hypothetical business models with which a super-inventive en-vogue entrepreneur like Elon Musk could one day surprise his or her German counterparts (Gupta, 2017).

The authors of the article "Forks in the Road: Navigating Industry Disruption" have a similarly paradoxically optimistic warning regarding the transient nature of current business models: "Auto industry incumbents, like those in many industries, have until recently faced a classical environment, which is stable and predictable, and where scale is an advantage. The auto industry now faces increasing unpredictability from changes in technology, consumer trends, and regulations. The same forces also create greater malleability and the opportunity to shape industry evolution by influencing technology, customer preferences, and regulatory standards, often through collaboration with other players.". (Reeves, Bergman, Gourévitch and Ortiz, 2016) 


\section{Methodology - The imperative necessity of integrating new variant factors into the algorithm pertaining to the business model concerned with electric automobile personal mobility}

Although seemingly too essayistic in style, our approach is nonetheless - hopefully, significant enough to be of economic value. We have succeeded in pointing out a whole series of conjunctural factors - which, through their relativity, variability and unpredictability, seem at first sight to complicate the conceptualization of business models appropriate to personal mobility with an electric car. However, the current lack of editorial space limits the amount of analysis we can dedicate to each individual factor.

Sensitive to our subjectivity towards some factors, we chose from the chapter of the factor generically formulated as a "change in mobility needs", a problem that we have called minimalistically called "half-dimensioning." Referring both to the sizing of cars and to the urban dimensioning of personal mobility by automobile, the problem is based on two related premises: the occupancy of large and medium-sized passenger cars and the suffocation of cities - such as space and pollution, suffocation due in part the uselessness of moving and parking of unused volumes. As was the case with the design, the emergence of "short" cars, such as those in the "mini" and "micro" classes proved to be real revolutions back in the day (based on several aspects - including as business models), it becomes evident that based on the current energy and economic crises, it is imperative that this conjunctural motif be reconsidered.

A very interesting study by Charlie Sorrel in 2016, augmented with video animation, demonstrates how much free space exists between cars in our cities (Sorrel, 2016). This claim was corroborated by analysing existing statistical data as well as by conducting personal measurements- and as you will see below, the results prove that that vast majority of automobiles capable of seating 5 persons usually only reach an average occupancy level of 1,6 occupants.

Because we wanted to capture the current level of occupancy of large and medium cars (with 5 places) in traffic, we also made a measurement, on November 8, 2017 on a sample of 1230 cars / day, within 12 hours (from 7.00 to 19.00), in three European cities with roughly the same number of cars / number of inhabitants: Brussels, Dusseldorf and Bucharest. Three teams of two operators recorded the gross values, after which they were processed in numerical and percentage terms. The graph in Figure 1 shows the resulting synthetic values. 


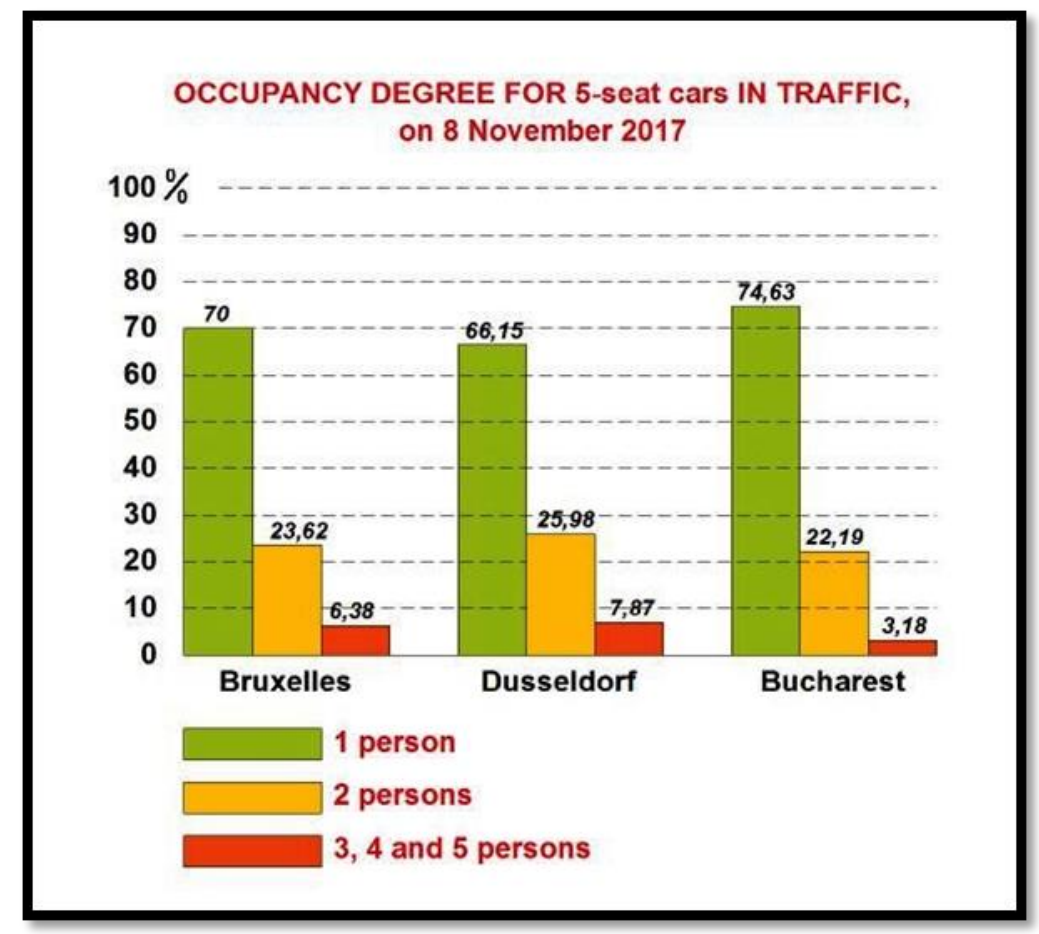

PICBE | 404

Figure 1. Comparative graph of occupancy degree for 5 seat cars, in traffic in three major cities in Europe, on the 8th of November 2017

Average occupancy index, as follows: Brussels $=1,36$, Dusseldorf $=1,42$, Bucharest $=1,28$. The values are slightly lower than those of the statistics we consulted and to which we then compared, which means either a slight downward trend in the characteristic indices or differences resulting from the slightly random choice given by the measurement constraints. However, this aspect is not currently relevant, nor is the comparison between the three cities, but rather the fact that large and medium cars carrying more than two people (the driver is included) are not, on average, more than $5.81 \%$. We appreciate that this percentage does not justify why, for a city with, for example, 1 million registered cars, 941,900 cars occupied by only 1 and 2 people, "in vain" - according to our calculations, a total area of approx. 3,350,000 sq. M., which is equivalent to about nine parks "Wildpark im Grafenberger Wald" in Dusseldorf, or about 11 parks "du Cinquantenaire" in Brussels, or about two "Herastrau" parks in Bucharest. If the same surface is reported at the current characteristic demographics of the three cities, would result in residential areas for about 14,900 inhabitants in Brussels, or for 9,080 inhabitants in Dusseldorf, or for 27,850 inhabitants in Bucharest.

Another conjectural factor that has been largely ignored, up until now, is genius. By following the evolution of specific businesses within the history of the automotive industry, we can observe that each strategic-managerial "revolution" is indissolubly tied to a technological breakthrough belonging to a person of remarkable intellectual prowess. Ford's introduction of conveyor belt manufacturing - at the beginning of the twentieth century, Citroen's traction on the front wheels in 1948, or the compacting of body volumes started in 1959 by Alec Issigonis - for Mini and then continued with the Smart Micro-Compact in 1998, built by the collaboration between Mercedes-Benz AG and SMH AG based on a concept of only 2.5 meters in length since 1972, by Johann Tomforde - the designer of Mercedes-Benz, are just some examples of the overwhelming importance of genius in the proliferation of a business. There is no doubt that bright individuals exist in every company, but we now emphasize the necessity of that 
providential uniqueness that can bring, through its ingenuity, a major advantage in the competition of a firm with other competitors. The problem for a company, in this case, would be to identify that "bright bulb", which is not always an easy task. And here's how this genius factor, inappropriately addressed by the traditional business mechanism - as we have already said - is also required in the design of new BMECs as a conjectural leverage for businesses that want to be more controllable and adequate, more "comfortable", or safer within their respective markets. "Tesla Motors is not simply an automaker. It is an "energy innovation company," a critical element in its broader quest for "zero emission power generation.", said Matthew N. Eisler, quoting the same Elon Musk. (Eisler, 2016)

\section{Results and conclusions}

By heavily promoting the idea of micro and mini automobiles, thereby arguing for a "reduction by half" of all automobile sizes, we could cause a significant relief to cities, even if there would not be a reduction by half in the space currently occupied. If the electric car supplier would secure for the buyer, within the same contract, the guaranteed availability of a large or medium-sized car for long-stay holidays and weekends, or the availability of another "stylish" distance transport such as train, coach, airplane, boat, etc., supplemented by the guaranteed availability of a car that the customer can use in the destination, the offer would become difficult to refuse.

Although the opposition between the electric and the traditional automobile has bellicose connotations, history has already deemed who is to be lose this particular battle. Whether future personal mobility is electric (or not) is of less importance/interest than the actual incontestable fact that mobility based on fossil fuel will eventually disappear completely. Perhaps that is why, at least yet, the present "war" - which does not promise to last "a hundred years", seems rather a competition between "two roses".

The world will remain incurably optimistic - our humble opinion, influenced by the human nature manifests itself and the fascination of already established success, of models like Xerox, Hilti, Uber and Tesla, even if the "topic issue" continues to exist and persist as such in the consciousness of everyone and especially in the minds of entrepreneurs. This state of affairs is therefore, at least morally, an indicative answer from the theoretical research. It is also the reason that argues our entire doctoral and correspondingly our present editorial approach. Although we have not been able to analyse, in detail, all the conjuncture factors that have sparked our interest, we are grateful for the fact that we have succeeded, by focusing on some of them, to provoke a conventional disillusionment and to disengage from hypothetical prejudices for future approaches.

\section{References}

Crânganu, C. "Automobilul electric = automobilul viitorului? Argumente pro și contra". (2016). http://www.contributors.ro/economie/automobilul-electricautomobilul-viitorului-argumente-pro-\%C8\%99i-contra/, accessed at 26 Aug. 2017.

Dimitropoulos A., Ommeren J.N.(van), Koster P., Rietveld P., 2016, "Not fully charged: Welfare effects of tax incentives for employer-provided electric cars", Journal of Environmental Economics and Management, Volume 78, July 2016, Pages 1-19, (http://www.sciencedirect.com/science/article/pii/S009506961600005X) (accesed at November 02, 2016). 
Eisler M.N., 2016, "A Tesla in Every Garage? Not So Fast. Elon Musk's sunny vision of the electric-car future sells well to the tech elite, but it won't captivate the masses", Posted 28 Jan 2016, https://spectrum.ieee.org/transportation/advanced-cars/atesla-in-every-garage-not-so-fast)

Gavrilescu, I. (2017). "Effective Business Models for Electric Vehicles", The 11th International Conference on Business Excellence Strategy, Complexity and Energy in changing times, 30-31 March 2017, Bucharest, România, Volume 11, Issue 1, Published Online: 2017-08-26 | DOI: https://doi.org/10.1515/picbe-2017-0004

Gupta, A., (2017), "Thus spake Dr. Dieter Zetsche / Chairman - Daimler AG.", https://www.linkedin.com/pulse/thus-spake-dr-dieter-zetsche-chairmandaimler-ag-amit-gupta

Lerch, C., Kley F.,Dallinger D. (2010) "New business models for electric cars. A holistic approach.", Working Paper Sustainability and Innovation No. S 5/2010. http://www.isi.fraunhofer.de/isi-wAssets/docs/e-x/working-paperssustainability-and-innovation/WP5-2010_businessmodels_electric-mobility.pdf, acceseed on 15 dec. 2016

Lutz B., 2017, "Bob Lutz: Kiss the good times goodbye. "Everyone will have 5 years to get their car off the road or sell it for scrap",

Oproescu, G. (2017). "Cum să-ţi furi căciula", http://yo4px.blogspot.ro/2017/06/cum-sa-ti-furi-caciula-de-gheorghe.html , accesed at 8 June 2017.

Osterwalder, A., Pigneur, Y., Tucci, C. L., (2005): "CLARIFYING BUSINESS MODELS: ORIGINS, PRESENT, AND FUTURE OF THE CONCEPT", https://pdfs.semanticscholar.org/01bb/3767f63880825ffa873c2e985f5df40780 5a.pdf, (accesed at 08 July 2016).

Reeves, M., Bergman, R., Gourévitch, A., and Ortiz, M., (2016). "Forks in the Road: Navigating Industry Disruption", www.bcgperspectives.com, accessed at 22 nov. 2017.

Sallay, D. (2013). "Marginal Costs and Benefits of Electric Cars". Salt Lake Community College. (https://sloshmo.files.wordpress.com/2013/07/econ-paper.docx) Accesed at 2 april.2017.

Sorrel C., "Cars need eight lanes to keep up with a single train moving the same amount of people", https://www.fastcompany.com/3063344/these-animated-videosshow-just-how-much-space-cars-waste-in-our-cities.

Tanţău, A.D., Khorshidi, M., (2016), "New business models for state companies in the oil industry", Management \& Marketing, ISSN (Online) 18420206, DOI: https://doi.org/10.1515/mmcks-2016-0011, https://www.degruyter.com/view/j/mmcks.2016.11.issue-3/mmcks-20160011/mmcks-2016-0011.xml, accessed at 29 nov. 2017. 